\title{
Physical and Biological Controls of Copepod Aggregation and Baleen Whale Distribution
}

\author{
Mark Baumgartner and Rubao Ji \\ Woods Hole Oceanographic Institution \\ Biology Department, MS \#33 \\ 266 Woods Hole Road \\ Woods Hole, MA 02543 \\ phone: (508) 289-2678 fax: (508) 457-2134 email: mbaumgartner@whoi.edu \\ phone: (508) 289-2986 fax: (508) 457-2134 email: rji@whoi.edu \\ Changsheng Chen \\ School for Marine Science and Technology \\ University of Massachusetts-Dartmouth \\ 706 South Rodney French Blvd \\ New Bedford, MA 02744 \\ phone: (508) 910-6388 fax: (508) 910-6371 email: c1chen@umassd.edu \\ Award Number: N000140811200 \\ http:// www.whoi.edu/sites/mbaumgartner
}

\section{LONG-TERM GOALS}

Our long-term goal is to develop a fundamental understanding of the physical and biological mechanisms that aggregate zooplankton on spatial scales of hundreds of meters to hundreds of kilometers. These aggregation processes have a profound effect on the distribution, movements, and behavior of top predators, including those that feed directly on zooplankton (e.g., basking sharks, manta rays, right whales). While all marine mammals rely on prey aggregation processes for their survival, baleen whales are perhaps most dependent upon these processes because of the enormous quantities of food they must consume daily. Therefore, we have chosen to focus our long-term research efforts on the interactions between baleen whales, zooplankton, and ocean physics to better understand the environmental factors influence marine mammal distribution.

\section{OBJECTIVES}

The objectives of this study are to

- Elucidate the mechanisms of copepod aggregation in the Great South Channel, a major springtime feeding area for right, sei, humpback, and fin whales in the southwestern Gulf of Maine

- Examine the relationship between these mechanisms and the distribution and abundance of baleen whales 


\section{Report Documentation Page}

Form Approved

OMB No. 0704-0188

Public reporting burden for the collection of information is estimated to average 1 hour per response, including the time for reviewing instructions, searching existing data sources, gathering and maintaining the data needed, and completing and reviewing the collection of information. Send comments regarding this burden estimate or any other aspect of this collection of information,

including suggestions for reducing this burden, to Washington Headquarters Services, Directorate for Information Operations and Reports, 1215 Jefferson Davis Highway, Suite 1204, Arlington

VA 22202-4302. Respondents should be aware that notwithstanding any other provision of law, no person shall be subject to a penalty for failing to comply with a collection of information if it

does not display a currently valid OMB control number.

1. REPORT DATE

2010

2. REPORT TYPE

3. DATES COVERED

00-00-2010 to 00-00-2010

4. TITLE AND SUBTITLE

Physical and Biological Controls of Copepod Aggregation and Baleen Whale Distribution

6. $\operatorname{AUTHOR}(\mathrm{S})$

7. PERFORMING ORGANIZATION NAME(S) AND ADDRESS(ES)

Woods Hole Oceanographic Institution,Biology Department,266 Woods

5a. CONTRACT NUMBER

5b. GRANT NUMBER

5c. PROGRAM ELEMENT NUMBER

Hole Road,Woods Hole,MA,02543

9. SPONSORING/MONITORING AGENCY NAME(S) AND ADDRESS(ES)

10. SPONSOR/MONITOR'S ACRONYM(S)

11. SPONSOR/MONITOR'S REPORT

$\operatorname{NUMBER}(\mathrm{S})$

12. DISTRIBUTION/AVAILABILITY STATEMENT

Approved for public release; distribution unlimited

13. SUPPLEMENTARY NOTES

14. ABSTRACT

15. SUBJECT TERMS

16. SECURITY CLASSIFICATION OF:

a. REPORT

unclassified b. ABSTRACT

unclassified c. THIS PAGE

unclassified
17. LIMITATION OF ABSTRACT

Same as

Report (SAR)
18. NUMBER 19a. NAME OF

OF PAGES RESPONSIBLE PERSON

8 


\section{APPROACH}

We are using field observations collected in 2005-2007 (hydrography, whale distribution, zooplankton distribution, and drifter tracks; Figure 1), the state-of-the-art FVCOM circulation model, and an individual-based particle tracking model to investigate copepod aggregation, and hence baleen whale distribution, in the Great South Channel. Our original approach was as follows:

1. Validate FVCOM circulation fields

2. Conduct simulations with individual-based particle tracking model

3. Compare model results to in-situ observations

4. Characterize the physical-biological mechanisms that form and maintain copepod aggregations

We have compared the FVCOM hydrographic and circulation fields to in-situ observations (CTD and drifter data) to ensure the model is reasonably representing actual in-situ conditions, and then we have seeded the model with virtual copepods to track their advection through the study area. Copepods are represented in these simulations as Lagrangian particles that are either passive or exhibit diel vertical migration parameterized from in-situ observations of this migration behavior in the Great South Channel (see below).

Our initial approach was to compare the particle-tracking model results to the distribution of both whales and zooplankton derived from the 2005-2007 survey data; however, we have found that our zooplankton sampling was too coarse for this kind of direct comparison. Moreover, we have found that diel vertical migration has a profound influence on advection and retention of Calanus finmarchicus, the primary copepod prey of right and sei whales in this area. Since this behavior is variable (Baumgartner et al. submitted), we have found it difficult to compare model integrations with in-situ data. We changed our approach to focus more on process studies within the model framework to examine potential aggregation mechanisms at known locations of whale aggregations. An analysis of aerial survey results from 2004-2007 suggested that the southern part of the Great South Channel was a potential "hotspot" for right whales, and we focused our modeling efforts on understanding processes in this location. These efforts have not identified any regional scale processes that aggregate copepods, leading us to believe that large scale processes funnel vast quantities of copepods into the Great South Channel, and very small scale processes (a few kilometers or less in scale) act to aggregate these copepods into patches that are exploited by the whales. We conducted large-scale model runs to estimate how many copepods in the Gulf of Maine are flushed through the Great South Channel to quantify this funneling effect.

\section{WORK COMPLETED}

We accomplished the following tasks during the reporting period:

- Analysis of aerial survey data to identify "hotspots" of baleen whale occurrence

- Exploration of circulation features occuring in a right whale "hotspot"

- Simulation of large-scale springtime circulation in the Gulf of Maine to estimate copepod flushing through the Great South Channel 
- Completion and submission of a manuscript describing copepod diel vertical migration behavior and its influence on right and sei whale occurrence in the Great South Channel

\section{RESULTS}

We conducted an analysis of NOAA Northeast Fisheries Science Center aerial survey data collected during 2004-2007 in the Great South Channel to better estimate baleen whale distribution and to identify potential "hotspots" of baleen whale occurrence. On-effort survey periods and sightings of right and sei whales were tallied in a grid consisting of $5 \times 6$ nautical mile "boxes" to estimate relative abundance, also known as sightings per unit effort (Figure 2). Right whale abundance was highest in the southern portion of the Great South Channel near our oceanographic line 4 (Figure 3), whereas there was little spatial patterning to sei whale distribution other than a weak west-to-east trend in increasing abundance.

We seeded the FVCOM model with particles exhibiting both diel vertical migration and no migration behavior to investigate regional scale processes at the southern end of the Great South Channel along our oceanographic line 4. Our goal was to explain why this area appears to be a "hotspot" of right whale occurrence. Despite several model runs, we have been unable to observe an overt regional aggregation process that would explain the high abundance of right whales in this area. In all model runs, copepods are not retained in the region for any appreciable period of time. Although diel vertical migration tends to extend the period that copepods are retained, it does not appear to be long enough to accumulate copepods to any great extent. We are left with two conclusions from this work: (1) there is a regional aggregation process occurring that is not represented in the physics of the model or in our parameterization of copepod behavior, or (2) there are, in fact, no regional aggregation processes and instead, a combination of large scale processes $(>100 \mathrm{~km})$ and small scale processes $(<10 \mathrm{~km})$ are responsible for highly aggregated patches of copepods in this area. We are reasonably confident that the FVCOM is capturing the regional circulation accurately, as our drifter-model comparisons were quite favorable. Moreover, we paramaterized copepod behavior from an in-situ study of diel vertical migration, so we believe we are representing this accurately in the model. Therefore, we believe that if a regional scale process were occuring, we would have observed it in the model.

To investigate the possibility that large-scale processes may aid in the formation of large aggregations of copepods in the Great South Channel, we seeded a Gulf-of-Maine-wide large-scale FVCOM run with particles in the early spring and tracked their movement through the Gulf of Maine to estimate how many copepods spawned in the Gulf of Maine pass through the Great South Channel, and more specifically, how many copepods pass through the Great South Channel during the month of May, the period when right whales are most abundant there. Particles were released in the model 2 months prior to May to account for the roughly 2 month development period from egg to the C5 copepodid stage for Calanus finmarchicus. The results suggest that $25-30 \%$ of all copepods spawned throughout the Gulf of Maine in the early spring pass through the Great South Channel during the month of May (Figure 4). These results suggest that the Great South Channel acts as a funnel through which much of the Gulf of Maine C. finmarchicus population is forced, and that right and sei whales remain near the mouth of this funnel to take advantage of a stream of copepods passing by. To facilitate feeding, it appears smaller scale processes (those on scales of kilometers to hundreds of meters, i.e., those not well resolved in the FVCOM model) may serve a critical role in aggregating copepods into the small scale patches that we observe in the Great South Channel. 
Finally, we completed and submitted a manuscript characterizing the diel vertical migration (DVM) behavior of $C$. finmarchicus and the influence this behavior has on right and sei whale occurrence. This work was completed as part of this project because we hypothesized that DVM behavior can promote local aggregation. This study was based on in-situ observations of both copepod vertical distribution and right and sei whale occurrence that we collected at anchor stations during cruises to the Great South Channel during 2005-2007. From these data, we were able to parameterize DVM behavior for our modeling studies. Moreover, we found very interesting differences in right and sei whale occurrence during times of strong and weak diel vertical migration by $C$. finmarchicus that have important implications for both the distribution of these whales in the Gulf of Maine as well as competition with other $C$. finmarchicus predators such as herring and sand lance. Specifically, we found that sei whales were absent during periods of strong $C$. finmarchicus DVM, whereas right whale abundance was unaffected by DVM behavior. Sei whales appear to be restricted to feeding only on surface aggregations of copepods, but our tagging studies suggest that right whales can feed on $C$. finmarchicus both at the surface and at depth during day or night. In habitats with a deepwater refuge, C. finmarchicus is continuously available to right whales, but DVM behavior may significantly reduce predation by zooplantivorous fish. Over banks where C. finmarchicus cannot escape, zooplanktivorous fish likely have much greater control over local $C$. finmarchicus populations and can outcompete right whales. This hypothesis may explain why right whales are seldom observed directly over banks.

\section{IMPACT/APPLICATIONS}

By understanding aggregation mechanisms, critical marine mammal habitats can be better identified, studied, and ultimately protected. Risk managers need to account for the environmental factors that make particular areas attractive to marine mammals so that both human activities (e.g., fishing, shipping, Naval exercises) and marine mammals can coexist with minimal impact to each other. Research on the underlying processes that aggregate prey will ultimately inform our efforts to predict when and where interactions between human activities and marine mammals will occur.

\section{RELATED PROJECTS}

The project entitled "Right Whale Diving and Foraging Behavior in the Southwestern Gulf of Maine" (award number N000140910545, PI Mark Baumgartner) is closely linked to this project, as it is directly examining the response of North Atlantic right whales to the aggregation processes being investigated in this project.

\section{PUBLICATIONS}

Baumgartner, M.F., N.S.J. Lysiak, C. Schuman, J. Urban-Rich, and F. Wenzel. Diel vertical migration behavior of Calanus finmarchicus in the southwestern Gulf of Maine and its influence on right and sei whale occurrence. submitted to Marine Ecology Progress Series. (paper was accepted with minor revisions upon initial submission; revisions are now underway) 


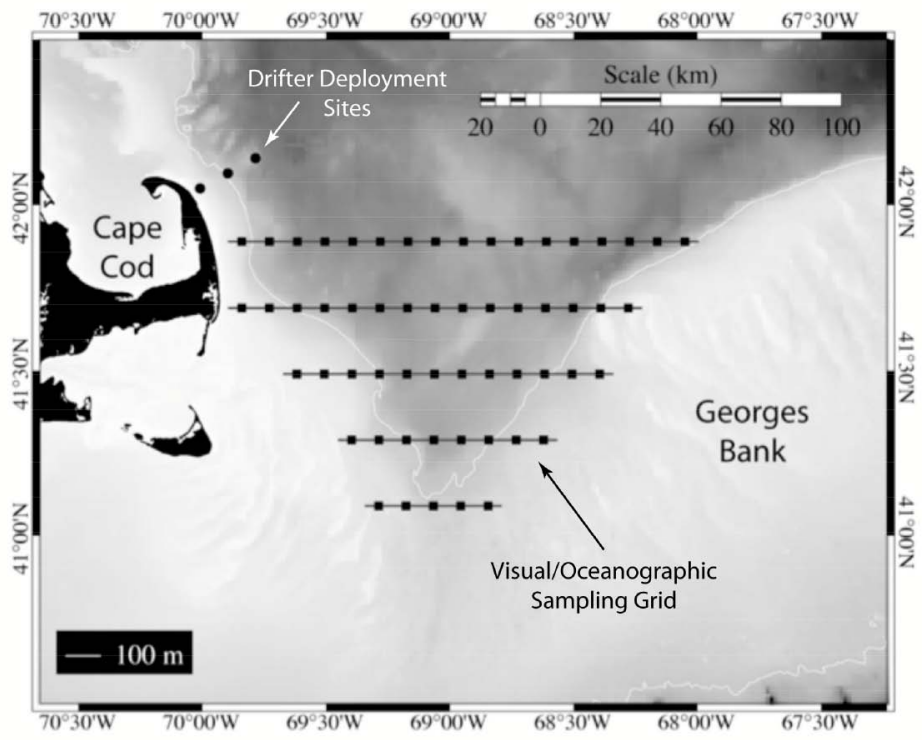

Figure 1. Visual and oceanographic station grid in the Great South Channel.

Surface drifter deployment sites also shown.

[Map of oceanographic station grid in the Great South Channel between Cape Cod, Massachusetts and Georges Bank] 

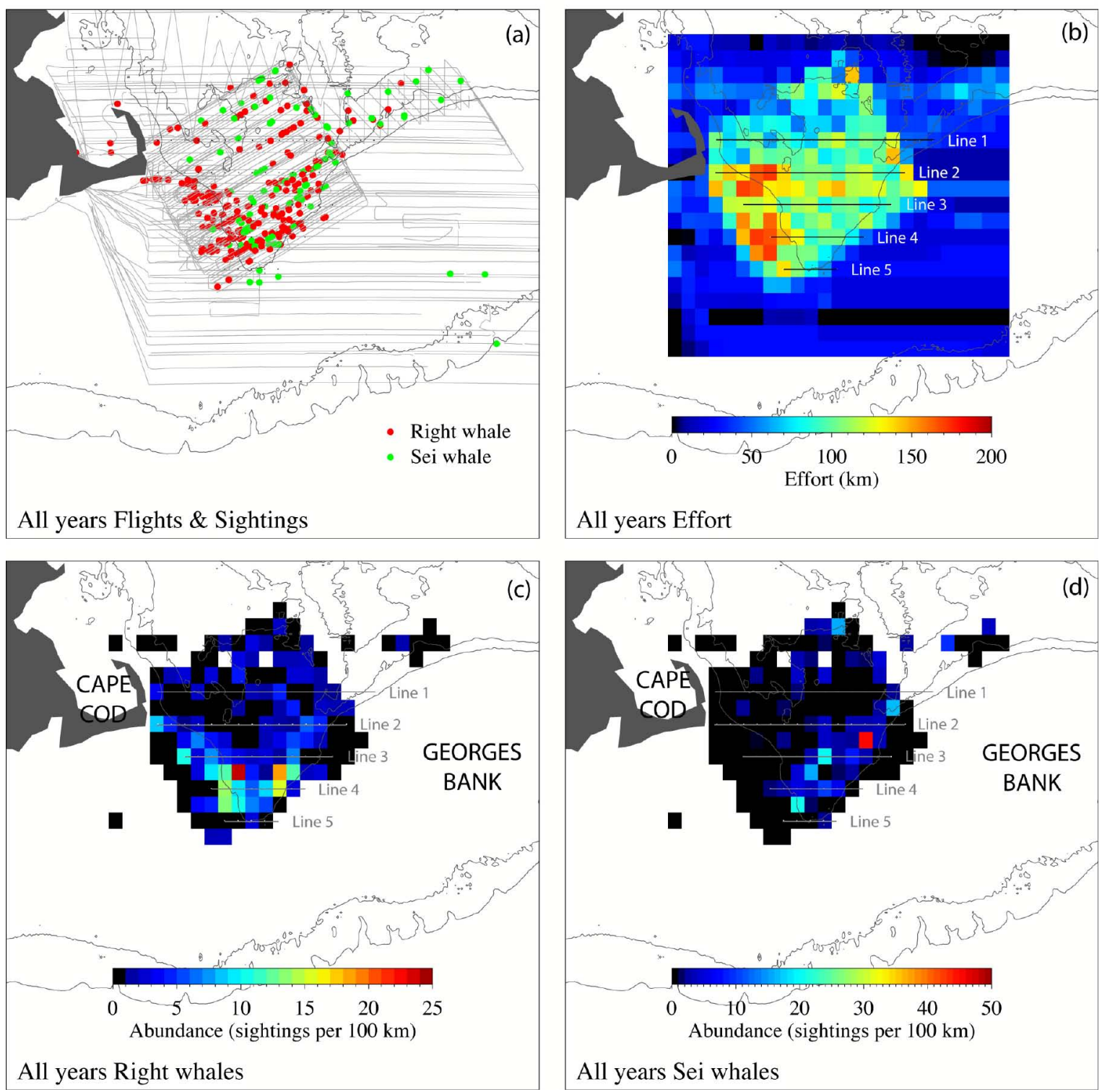

Figure 2. Summary of 2004-2007 aerial survey results. (a) Distribution of survey tracks (gray lines), right whale sightings (red dots), and sei whale sightings (green dots). (b) Total effort summarized over $5 \times 6$ nautical mile boxes expressed as the total distance traveled by the survey aircraft in each box. Locations of oceanographic transects (lines 1-5) also shown. (c) Relative abundance of right whale sightings for all years. (d) Relative abundance of sei whales for all years. [Maps of sighting effort and relative abundance of right and sei whales in the Great South Channel between Cape Cod, Massachusetts and Georges Bank] 

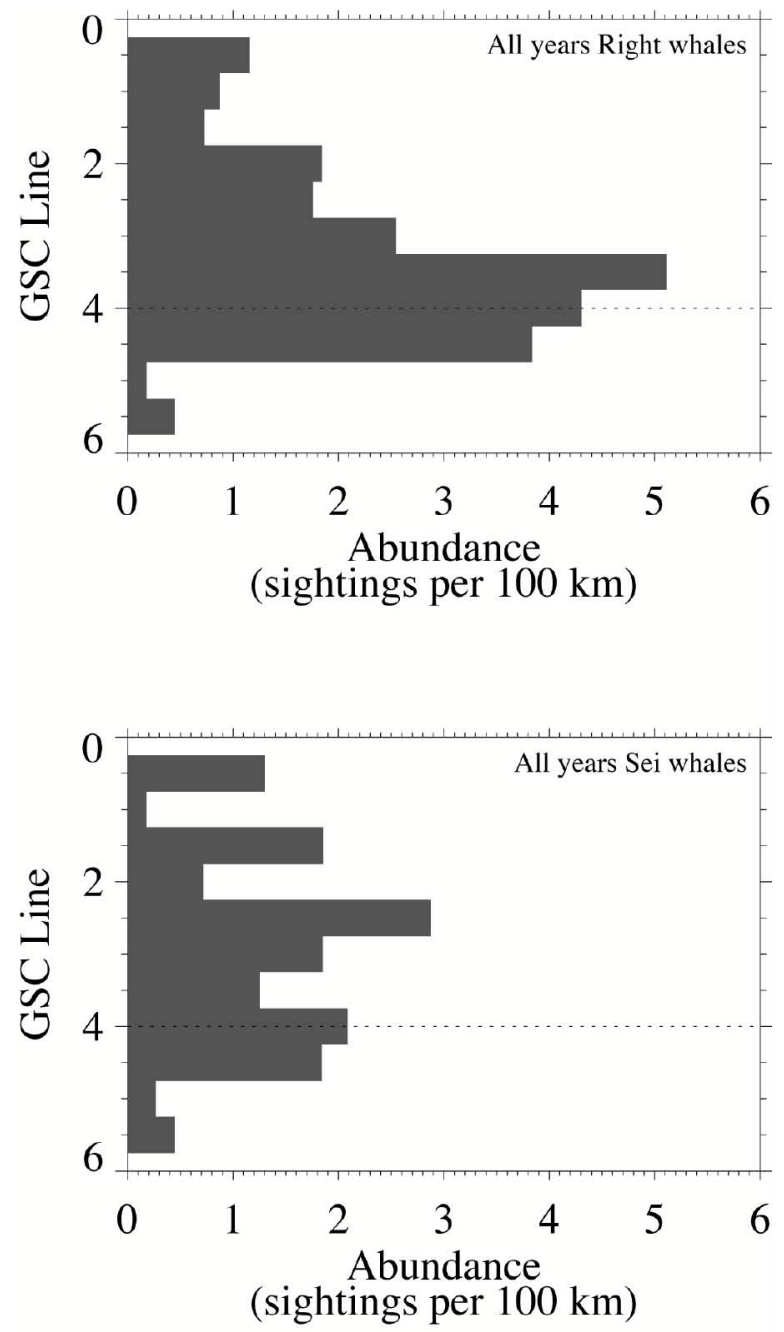

Figure 3. Relative abundance of right (upper panel) and sei (lower panel) whales in the Great South Channel averaged along each oceanographic transect line.

[Plots of relative abundance of whales in the Great South Channel showing strong concentration of right whale sightings along transect line 4 and no similar concentration of sightings for sei whales.] 


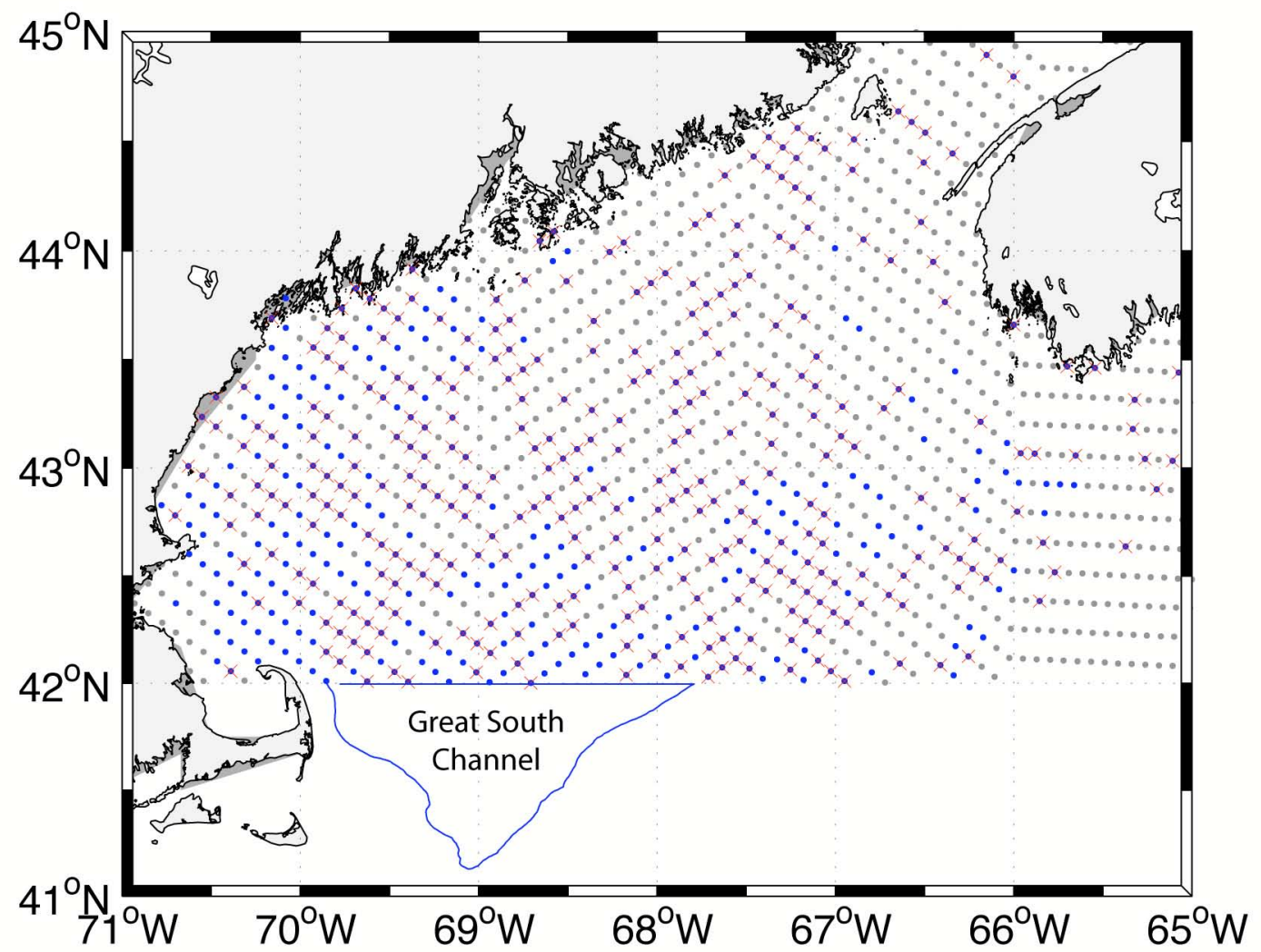

Figure 4. Results of 2005 Gulf-of-Maine-wide large scale FVCOM tracking model run showing the distribution of particle seed locations (gray dots), particle seed locations for particles that later passed through the Great South Channel (blue dots), and particle seed locations for particles that later passed through the Great South Channel during May (red crosses). Particles were released in the FVCOM on March 1, 2005. In this model run, $43 \%$ of all particles released passed through the Great South Channel, and $27 \%$ of all particles passed through the Great South Channel during May.

[Map of particle distribution in the Gulf of Maine showing most particles that pass through the Great South Channel originate in the western and central Gulf of Maine.] 